\title{
Dashboard Monitoring Website Dosen Studi Kasus Universitas Bina Darma
}

\author{
Iqbal Wahyudi \& Ahmad Syazili \\ Fakultas Teknik Ilmu Komputer, Universitas Bina Darma \\ Email: iqbalwahyudi718@gmail.com
}

\begin{abstract}
The concept of dashboard performance is an information system application model provided for managers to present performance quality information, from a company or organizational institution, dashboards have been widely adopted by companies or businesses. In this study, the authors designed a dashboard that was used as a monitoring system for lecturer posting activities at Binadarma University, Palembang. The limitation of the dashboard in this study only displays data based on lecturer posts which will be developed in the form of a website. Dashboard design is more effective and efficient than viewing data manually, which requires managers to open a database to view data one by one from lecturers' posts. In making the lecturer website dashboard, the data taken is in the form of posting data stored in the lecturer database, the data that has been taken will be presented in the dashboard in the form of graphs, tables and dashboards.
\end{abstract}

Keyword : dashboard performance concept, dashboard design, monitoring

\section{Pendahuluan}

Dashboard merupakan sebuah model aplikasi sistem informasi yang disediakan bagi para manager untuk menyajikan informasi kualitas kinerja, dari sebuah perusahaan atau lembaga organisasi. Dashboard telah banyak digunakan perusahaan. Malik melakukan penelitian dengan menggunakan terminology "Enterprise Dashboard" yang diartikan sebagai dashboard yang merupakan sebuah komputer interface yang menyajikan informasi dalam bentuk tabel, laporan, indikator visual dan mekanisme peringatan dinamis serta relevan.

Di era modern seperti sekarang ini, teknologi informasi komputer sangat maju, setiap orang dapat dengan mudah mengakses berbagai informasi dengan cepat bahkan dari jarak yang sangat jauh. Karena perkembangan tersebut, saat ini teknologi informasi telah banyak digunakan oleh perusahaan untuk bisnis. Tidak bisa dihindari bahwa teknologi sangat dibututhkan. Bagi perusahaan sangatlah penting mengetahui teknologi informasi. Organisasi. menghadapi lingkungan bisnis yang berubah dengan cepat. demi tercapainya tujuan yang telah ditetapkan pihak perusahaan melakukan monitoring dan pengukuran kinerja secara terus menerus. dalam melakukan monitoring kinerja membutuhkan informasi dan data yang diambil dari data yang tersedia. sehingga hasil monitoring dapat disampaikan kepada perusahaan secara tepat waktu.

Begitu juga dengan sistem informasi yang sudah banyak digunakan hampir diseluruh instansi baik pemerintah maupun swasta, Universitas Bina Darma terdapat beberapa aktifitas dosen salah satunya merupakan aktifitas postingan dosen. Akan tetapi, untuk mengetahui aktifitas dosen tersebut pengelola diharuskan membuka satu persatu database. Hal tersebut kurang efisien dan efektif ketika melakukan monitoring aktifitas dosen dikarenakan akan memakan waktu. Untuk mempermudahkan memonitoring aktifitas dosen, peneliti melakukan perancang dashboard untuk monitoring postingan 
dosen di Universitas Bina Darma. Dengan batasan sistem dashboard ini hanya memonitoring postingan website dosen dan dikembagkan dalam bentuk dashboard berupa grafik, tabel dan dashboard. Untuk terbentuknya dashboard monitoring website dosen di perlukan data postingan dosen. Data postingan dosen tersebut diambil dari kumpulan database, kemudian setiap dosen memiliki satu database tersendiri dan terdiri dari postingan dosen. Dengan adanya dashboar untuk monitoring ini diharapkan akan mempermudah pengelola melakukan monitoring dan juga bisa meningkatkan permorfa dari dosen.

\section{Tinjauan Literatur}

\subsection{Sistem Informasi}

Menurut (Yakub, 2012), sistem informasi adalah kombinasi terorganisir dari orang, perangkat keras, perangkat lunak, jaringan komunikasi, dan sumber daya yang mengumpulkan, mengubah, dan menyebarkan informasi dalam suatu organisasi. Selain itu, sistem informasi adalah kombinasi atau kombinasi dari orang, perangkat lunak (hardware), perangkat lunak, dan sumber daya data yang mampu mengumpulkan, memproses, mengubah, dan menyebarkan informasi dalam suatu organisasi.

Menurut Gordon B. Davis (1991:8), Sistem informasi merupakan suatu sistem yang menerima input atau masukan data dan instruksi, mengolah data sesuai dengan instruksi dan mengeluarkan hasilnya.

Menurut John F. Nash (1995:8), Sistem informasi adalah kombinasi dari manusia, fasilitas atau alat teknologi, media, prosedur dan pengendalian yang ditujukan untuk mengatur jaringan komunikasi yang penting, proses transaksi tertentu dan rutin, membantu manajemen dan pemakai intern dan ekstern dan menyediakan dasar untuk pengambilan keputusan yang tepat.

Menurut Lani Sidharta (1995:11), Sistem informasi adalah sistem buatan manusia yang berisi himpunan terintegrasi dari komponen - komponen manual dan komponenkomponen terkomputerisasi yang bertujuan untuk mengumpulkan data, memproses data, dan menghasilkan informasi untuk pemakai.

Dari penjabaran diatas bisa disimpulkan bahwa sistem informasi adalah sutu kombinasi terartur apapun dari hardware, software, database ( basis data ) dsb, yang di olah sehingga dapat mengumpulkan data, memproses data, dan menghasilkan informasi untuk pemakai.

\subsection{Dashboard}

Dashboard adalah alat yang menyediakan antarmuka visual, yang menggabungkan dan menyajikan informasi penting untuk mencapai tujuan tertentu secara sekilas. Tampilan visual dashboard yang mampu mengkomunikasikan informasi dengan jelas, cepat, dan memberikan persepsi benar-benar menjadi kunci keberhasilan dashboard. Konsep visualisasi data dan informasi akan digunakan saat merancang antarmuka dashboard. Visualisasi data dan informasi terkait hal-hal mengenai persepsi visual dan media penyajian data, penyampaian komponen dashboard harus mengutamakan estetika, ergonomis, dan efektifitas penyampaian informasi untuk memudahkan pengguna melihat, memantau dan membantu dalam mengambil keputusan yang tepat. dalam waktu nyata. Dashboard dinyatakan dalam beberapa istilah berbeda di pustaka yang ada.

\subsection{PHP}

Published by:

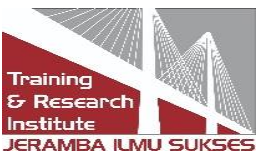


Menurut Raharjo (2011) Hypertext Preprocessor atau biasa disebut dengan PHP merupakan bahasa pemrograman script yang paling banyak digunakan saat ini. PHP banyak digunakan untuk memprogram situs website dinamis, meskipun dimungkinkan untuk menggunakannya untuk kegunaan lain. $P H P$ adalah bahasa yang hanya bisa dijalankan di server yang hasilnya bisa ditampilkan di client. PHP telah dibuat terutama untuk penggunaan web dan dapat menghubungkan kueri database. PHP sebenarnya merupakan program yang berjalan pada platform LINUX, sehingga menjadikan program ini sebagai freeware. Selanjutnya dikembangkan PHP yang dibuat dalam versi windows.

\subsection{Laravel}

Laravel adalah satu-satunya framework yang membantu Anda untuk memaksimalkan penggunaan $P H P$ di dalam proses pengembangan website. PHP menjadi bahasa pemrograman yang sangat dinamis, tapi semenjak adanya Laravel, dia menjadi lebih powerful, cepat, aman, dan simpel. Setiap rilis versi terbaru, Laravel selalu memunculkan teknologi baru di antara framework PHP lainnya.

Laravel diluncurkan sejak tahun 2011 dan mengalami pertumbuhan yang cukup eksponensial. Di tahun 2015, Laravel adalah framework yang paling banyak mendapatkan bintang di Github. Sekarang framework ini menjadi salah satu yang populer di dunia, tidak terkecuali di Indonesia.

Laravel fokus di bagian end-user, yang berarti fokus pada kejelasan dan kesederhanaan, baik penulisan maupun tampilan, serta menghasilkan fungsionalitas aplikasi web yang bekerja sebagaimana mestinya. Hal ini membuat developer maupun perusahaan menggunakan framework ini untuk membangun apa pun, mulai dari proyek kecil hingga skala perusahaan kelas atas. Laravel mengubah pengembangan website menjadi lebih elegan, ekspresif, dan menyenangkan, sesuai dengan jargonnya "The PHP Framework For Web Artisans". Selain itu, Laravel juga mempermudah proses pengembangan website dengan bantuan beberapa fitur unggulan, seperti Template Engine, Routing, dan Modularity.

\subsection{Bootstrap}

Bootstrap merupakan sebuah library framework CSS yang telah dibuat khusus uintuk mengembangkan front end sebuah website. Bootstrap juga dikenal sebagai salah satu framework CSS, HTML, Javascript yang begitu populer di kalangan website developer atau pengembang website. Apa itu bootstrap dan fungsinya? yang pasti bootstrap digunakan untuk mengembangkan website agar lebih responsive. Dengan adanya bootstrap tersebut tentu saja membuat halaman website bisa menyesuaikan dengan ukuran monitor device. Baik jika di akses lewat ponsel, tablet ataupun desktop. Awal mulanya, bootstrap sendiri bernama Twitter Blueprint.

\section{6 Хатрр}

Menurut Aditama (2013), Xampp adalah salah satu paket software web server yang terdiri dari Apache, MySQL, PHP dan PhpMyAdmin. Xampp dapat diperoleh dari situs apachefriend.org.

\subsection{HTML ( Hypertext Markup Language )}

HTML singkatan dari Hyper Text Markup Language, dokument HTML adalah file teks murni yang dapat dibuat dengan editor text sembarang. Dokumen ini dikenal sebagai 
webpage. Dokument HTML merupakan dokumen yang disajikan dalam browser web server. Dokument ini umumnya berisi informasi ataupun interface aplikasi di dalam internet. Ada dua cara untuk membuat sebuah web page : dengan HTML editor teks biasa (misalnya notepad). dan dapat juga dengan web editor misalkan Microsoft Front Page atau dengan Macromedia Dreamweaver Sebelum kita mengenal apa itu HTML ada baiknya kita mengetahui dulu apa itu HTTP (hypertext transer protokol). HTTP merupakan protokol yang digunakan untuk mentransfer data atau dokumen antara web server ke web browser (Netscape,Internet Explorer dll). Dan protokol ini sewaktu melakukan transfer, dokumen atau data web-nya dengan menggunakan format HTML. HTML sendiri adalah singkatan dari "hypertext markup language". Disebut dengan markup language karena HTML berfungsi untuk memperindah file tulisan (text) biasa untuk dapat dilihat pada web browser-web browser yang ada.

\subsection{CSS}

Menurut Kadir (2013), CSS adalah kode yang ditujukan untuk mengatur tampilan halaman web. Menurut Khafidli, CSS (Cascading Style Sheet) merupakan salah satu bahasa pemrograman web yang berguna untuk mengendalikan beberapa elemen dalam sebuah web sehingga lebih terstruktur dan seragam.

\subsection{Browser Web}

Browser web adalah software yang digunakan untuk menampilkan informasi dari server web. Software ini kini telah dikembangkan dengan menggunakan user interface grafis, sehingga pemakai dapat dengan mudah melakukan "point dan click" untuk pindah antar dokument. Di saat perkembangan $w w w$ ada dua browser web yang populer yaitu Internet Explorer (IE) dan Netscape Navigator. Namun saat ini bermunculan browser web lain yang turut meramaikan persaingan untuk merebut para pengguna internet.

Di antara browser web yang telah banyak digunakan pada saat peluncurannya adalah MSN , Opera dan Mozilla Firefox. Diantara browser web ini terdapat kelebihan dan kekurangan sehingga pengguna dapat memilih sesuai keinginan dan kemudahan yang ditawarkan.

\section{$2.10 \mathrm{Mysql}$}

Menurut Kadir (2013), MySQL tergolong sebagai DBMS (DataBase Management System). Perangkat lunak ini bermanfaat untuk mengelola data 35 dengan cara yang sangat fleksibel dan cepat. Berikut adalah sejumlah aktivitas yang terkait dengan data yang didukung oleh perangkat lunak tersebut:

1. Menyimpan data ke dalam tabel.

2. Menghapus data dalam tabel.

3. Mengubah data dalam tabel.

4. Mengambil data yang tersimpan dalam tabel.

5. Memungkinkan untuk memilih data tertentu yang diambil.

6. Memungkinkan untuk melakukan pengaturan hak akses terhadap data.

MySQL banyak dipakai untuk kepentingan penanganan database karena selain handal juga bersifat open source. Konsekuensinya perangkat lunak ini dapat dipakai oleh siapa 


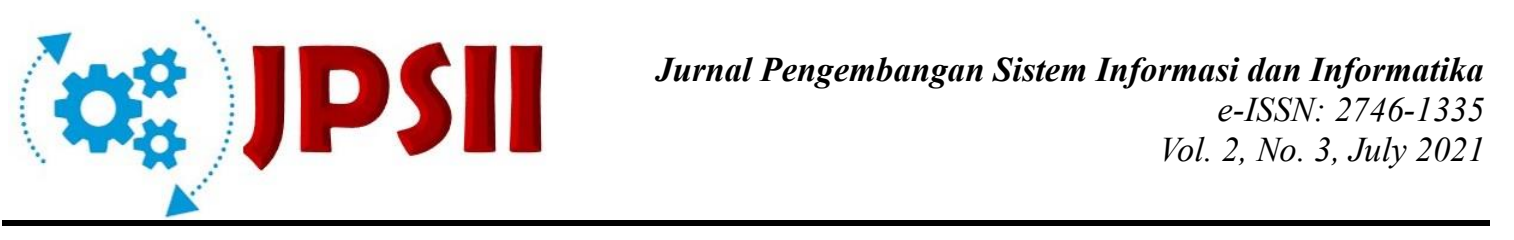

saja tanpa membayar dan source code-nya bisa diunduh oleh siapa saja.

\section{Metode Penelitian}

Untuk memperoleh data yang tepat dan akurat demi kesempurnaan aplikasi sistem yang akan dibuat, diperlukan suatu metode penelitian. Metode yang diambil dalam penelitian ini merupakan Metode Studi Kasus. Studi Kasus berasal dari terjemahan dalam bahasa Inggris "A CaseStudy" atau "Case Studies". Kata "Kasus" diambil dari kata "Case" yangmenurut Kamus Oxford Advanced Learner's Dictionary of Current English 3(1989; 173), diartikan sebagai :

1. Instance or example of the occurance of sth (contoh kejadian sesuatu).

2. Actual state of affairs situation (kondisi aktual dari keadaan atau situasi).

3. Circumstances or specialconditions relating to a person or thing.( lingkungan atau kondisi tertentu tentang orang atau sesuatu).

Dari penjabaran definisi tersebut dapat disimpulkan bahwa studi kasus adalah rangkaian kegiatan ilmiah yang dilakukan secara intensif, rinci dan mendalam tentang suatu program, peristiwa, dan kegiatan, baik pada individu, kelompok orang, institusi, atau tingkat organisasi untuk mendapatkan pengetahuan mendalam tentang acara tersebut. Biasanya peristiwa yang dipilih adalah peristiwa kehidupan nyata, yang sedang berlangsung, bukan sesuatu yang telah berlalu.

Metode studi kasus biasanya memperoleh data yang dibutuhkan melalui berbagai cara, mulai dari wawancara, observasi, atau pemeriksaan dokumen. Perbedaan metode ini dengan metode lainnya adalah ruang lingkup penelitiannya lebih terbatas, sehingga memungkinkan peneliti untuk melakukan penelitiannya secara lebih mendalam.

\subsection{Metode Pengumpulan Data.}

Untuk memperoleh data yang diperlukan dalam penyusunanan ini, penulis menggunakan metode pengumpulan data sebagai berikut :

1) Observasi

Pengumpulan data dikumpulkan secara langsung kepada Universitas Bina Darma untuk melihat sistem yang berjalan dan mencatat hasil observasi untuk menentukan proses yang akan berjalan kedepannya.

2) Wawancara

Pengumpulan data diperoleh dengan cara melakukan wawancara kepada pihak yang berkaitan mengenai pengambilan data di Universitas Bina Darma untuk mendapatkan informasi yang dibutuhkan.

3) Dokumentasi

Dokumentasi adalah suatu cara yang digunakan untuk memperoleh data dan informasi dalam bentuk buku, arsip, dokumen, tulisan angka dan gambar yang berupa laporan serta keteranganyang dapat mendukung penelitian.

\subsection{Metode Pengembangan}

Dalam Penelitian ini, penulis menggunakan metode pengembangan aplikasi prototype. Model prototype merupakan suatu metode pembuatan suatu sistem yang dibuat secara terstruktur dan memiliki beberapa tahapan yang harus dilalui dalam pembuatannya, namun jika pada tahap akhir dinyatakan bahwa sistem yang telah dibuat belum sempurna atau, maka sistem akan dievaluasi kembali dan akan melalui proses awal. Pendekatan 
Prototyping adalah proses berulang yang melibatkan hubungan kerja yang erat antara desainer dan pengguna. Tahapan metode prototype:

1) Analisis Kebutuhan

Di tahapan ini pengembangan melakukan identifikasi software dan semua kebutuhan sistem yang akan dibuat.

2) Membangun Prototype/Prototyping

Membangun protoyping dengan membuat perancangan sementara yang berfokus pada penyajian kepada pelanggan ( misalnya dengan membuat input dan format output).

3) Evaluasi Prototype/Prototyping

Evaluasi ini dilakukan untuk mengettahui apakah prototyping sudah sesuai denngan harapan pelanggan.

4) Pengkodean Sistem.

Pada tahap inni prototyping yang sudah disetujui akan diubah ke dalam bahasa pemograman.

5) Menguji Sistem

Ditahapan ini dilakukan untuk menguji sistem perangkat lunak yang sudah dibuat.

6) Evaluasi Sistem

Prangkat lunank yang sudah siap jadi akan dievaluasi oleh pelanggan untuk mengetahui apakah sistem sesuai dengan yang diharapkan.

7) Menggunakan Sistem

Perangkat lunak yang sudah diuji dan disetujui oleh pelanggan siap digunakan.

\section{Hasil dan Pembahasan}

\subsection{Hasil Penelitian}

Hasil dari penelitian adalah sebuah sistem dashboard monitoring website dosen studi kasus universitas binadarma. Data untuk monitoring didapatkan dari database dosen yang berjumlah 148, Database tersebut dijadikan menjadi 1 satabase dengan nama dashboard, agar database dashboard bisa mendapatkan data ketika dosen mengupload maka dalam pengkodingan terdapat fungsi yaitu tigger. Dimana trigger akan mengcopy data yang telah di input.

\subsection{Interface Dashboard Monitoring Website Dosen}

Terdapat beberapa interface untuk dashboard monitoring ini diantaranya adalah sebagai berikut.

1) Interface Home Pages

Pada interface ini, ada beberapa komponen yang ditampilkan. Diantaranya adalah count postingan dosen, count jumlah user, 10 dosen postingan terbanyak dan all postingan dosen. 


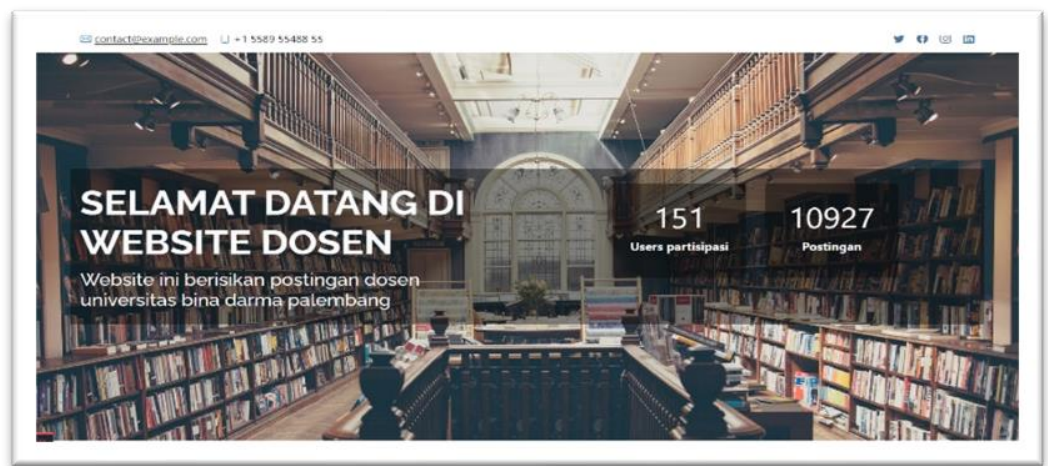

2) Interface Login Pages

Gambar 1. Home Pages

Halaman login pages hanya disediakan untuk admin, halaman login ada 2 parameter yang digunakan yaitu email dan password. Jika user tersebut berhasil login maka akan ditampilkan halaman dashboard ( halaman dashboard menampilkan menu diantaranya, dashboard, all user, trigger database, all postingan, role, permission, give permission dan user roles ) dan jika gagal maka akan redirec kehalaman login lagi.

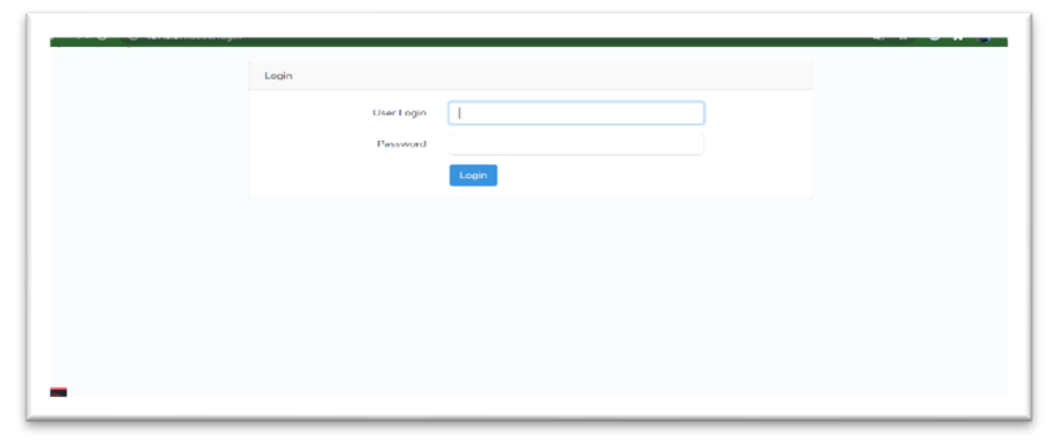

3) Interface Dashboard

Gambar 2. Login Paga

Pada halaman dashboard pages di tampilkan all postian user, all user, dan grafik dari postingan berdasarkan tahun dan bulan.

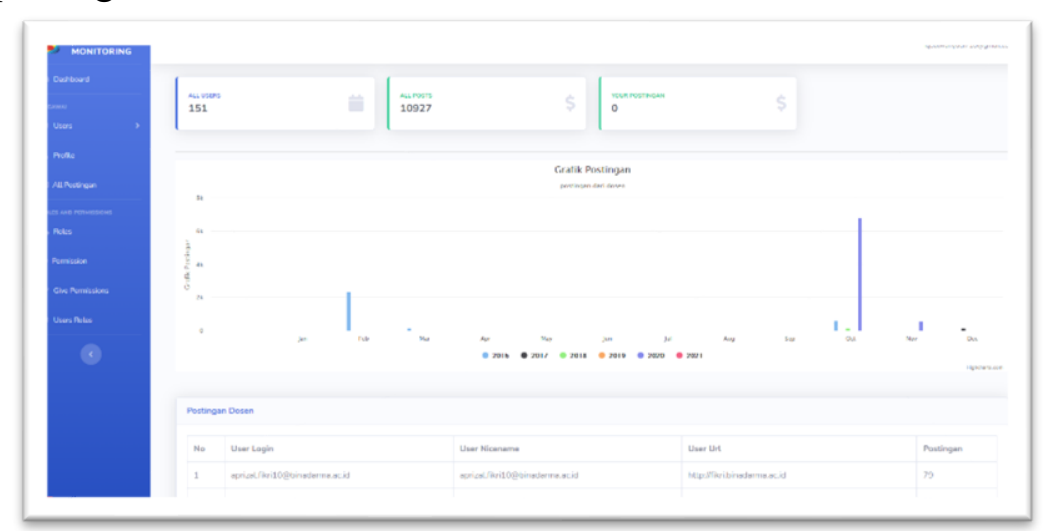

Gambar 3. Interface Dashboard

4) Interface all User

Pada halaman ini terdapat create user, update user dan delete user. Untuk bisa menjalankan perintah update user dan delete user hanya bisa dijalankan jika user 
login berroles admin jika roles login bukan admin maka hanya bisa create user dan tidak bisa edit ataupun delete user.

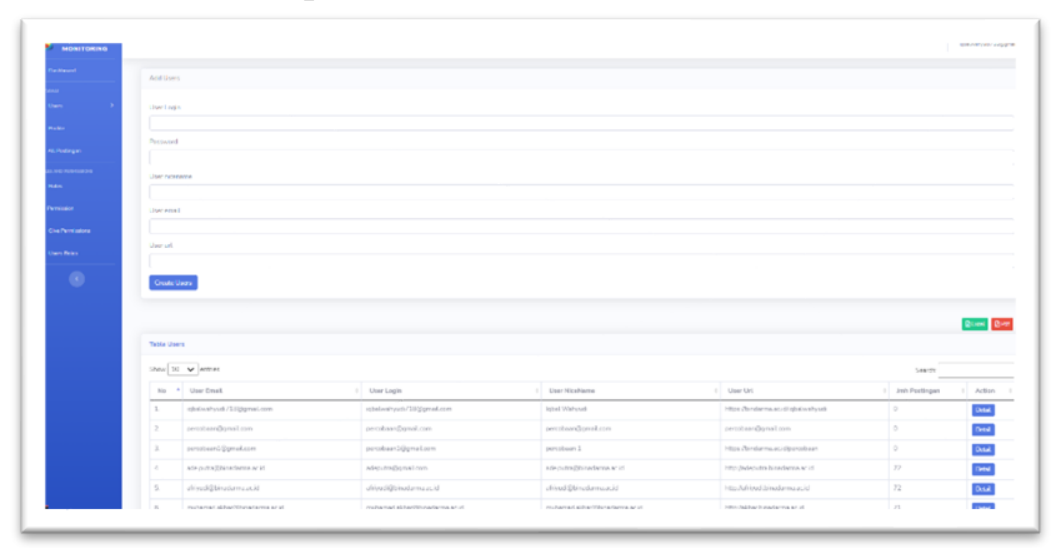

Gambar 4. All User

5) Interface Trigger

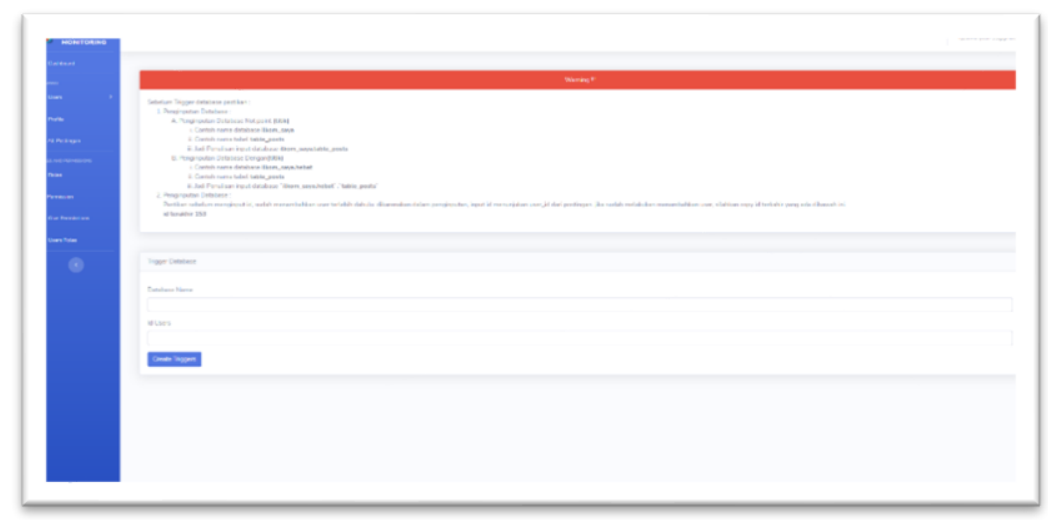

Gambar 5. Trigger

Pada interface trigger akan langsung ditampilkan untuk input terigger, dalam menginput trigger di berikan 2 parameter yaitu :

a) Masukkan nama database dan tabel

Ada 2 cara untuk memasukkan nama database dan tabel, diantaranya adalah nama database tanpa titik disetai nama tabel cara penulisannya adalah ( ilkom_saya.tabel_posts ) sedangkan database dengan titik disetai nama tabel maka penulisannya adalah (' ilkom_saya.titik'.'tabel_posts'). Untuk input nama database dengan titik diharuskan menggunakan back petik karena itu adalah query mysql untuk inputan dengan titik.

b) Masukkan id user

Id user disesuaikan dengan id user yang terdaftar di tabel user, dengan tujuan pada saat trigger akan sesuai dengan id user yang akan di tambah fungsi trigger.

\section{Kesimpulan}

Berdasarkan hasil penelitian, pengujian, implementasi serta pembahasan mengenai Dashboard Monitoring Website Dosen Studikasus Universitas Bina Darma maka didapatkan kesimpulan, penelitian ini menghasilkan website monitoring website dosen yang dilengkapi dengan grafik semua postingan, menambah users, pengaturan roles and permission dan juga dilengkapi dengan 


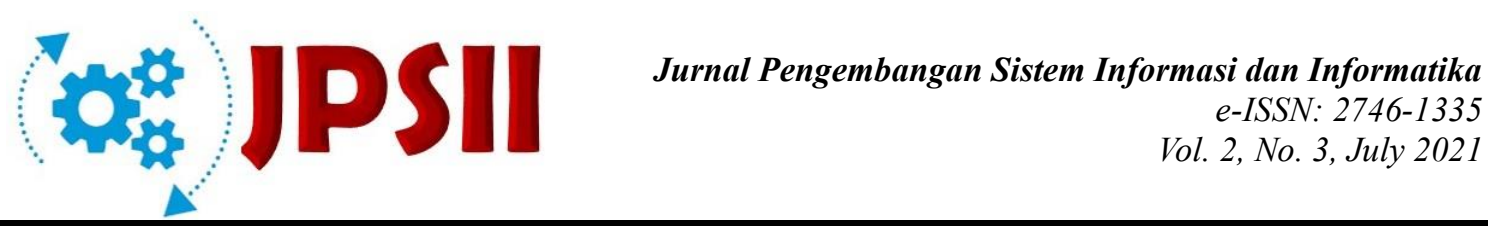

mentrigger antar databse melalui form input. Data yang digunakan adalah 148 database dengan 152 users ( users percobaan dan users dari 148 database tersebut) dan 10926 postingan dosen. Dengan 148 database yang dijadikan 1 database ( master $\mathrm{db}$ ) dan kemudian jika salah satu database tersebut insert ( menambah postingan ) secara otomtis akan tertambah juga di database master $\mathrm{db}$ karena telah di tambahkan query trigger yaitu after insert.

\section{Referensi}

"Pengetahuan Dasar dan Contoh Diagram Aktivitas". https://pccontrol.wordpress.com/2012/09/12/pengetahuan-dasar-dan-contoh-diagramaktivitas/, 12 september 2021.

"Statechart Diagram."http://myadsbo.blogspot.com/2018/01/statechart-diagram.html. JUMAT, 05 JANUARI 2018.web.

Antoni, D., \& Akbar, M. (2019). E-supply chain management value concept for the palm oil industry. Jurnal Sistem Informasi, 15(2), 15-29.

Antoni, D., Fikari, D., \& Akbar, M. (2018). The readiness of palm oil industry in enterprise resource planning. Telkomnika, 16(6), 2692-2702.

Antoni, D., Herdiansyah, M. I., Akbar, M., \& Sumitro, A. (2021). Pengembangan Infrastruktur Jaringan Untuk Meningkatkan Pelayanan Publik di Kota Palembang. JURNAL MEDIA INFORMATIKA BUDIDARMA, 5(4), 1652-1659.

Antoni, D., Jie, F., \& Abareshi, A. (2020). Critical factors in information technology capability for enhancing firm's environmental performance: case of Indonesian ICT sector. International Journal of Agile Systems and Management, 13(2), 159-181.

Arfan, R., \& Dipatiukur, J. (n.d.). SISTEM INFORMASI MONITORING DAN EVALUASI PEMBERIAN MODAL BANTUAN LPDB KEPADA KOPERASI DI DINAS KOPERASI UKM DAN PERINDUSTRIAN PERDAGANGAN. 3.

Fauzi, F., Dencik, A. B., \& Asiati, D. I. (2019). Metodologi Penelitian untuk manajemen dan akuntansi. Jakarta: Salemba Empat.

Few, S. (2006). Information dashboard design: The effective visual communication of data (1 st ed). O’Reilly.

Firman, A., Wowor, H. F., \& Najoan, X. (2016). Sistem Informasi Perpustakaan Online Berbasis Web. 8.

Guntoro. 2021, "Panduan Dasar Belajar UML (Unified Modeling Language)", https://badoystudio.com/uml/, diakses pada 2 juli 2021.

Januarita, D., \& Dirgahayu, T. (2015). Pengembangan Dashboard Information System (DIS). 7(2), 5 .

K, Yasin. 2019. "Laravel Framework: Pengertian, Keunggulan \& Tips untuk Pemula", https://www.niagahoster.co.id/blog/laravel-adalah/, diakses pada 2 juli 2021

Mardiani, G. T. (2013). SISTEM MONITORING DATA ASET DAN INVENTARIS PT TELKOM CIANJUR BERBASIS WEB. Komputa: Jurnal Ilmiah Komputer dan Informatika, 2(1). https://doi.org/10.34010/komputa.v2i1.78 
Monalisa, S. (2015). RANCANG BANGUN SISTEM INFORMASI MONITORING PERKEMBANGAN PROYEK BERBASIS WEB (STUDI KASUS: PT. INTI PRATAMA SEMESTA). 1(1), 6.

Nugroho, andy. 2019, "Apa Itu Bootstrap? Inilah Pengertian dan Cara Menggunakannya", https://qwords.com/blog/apa-itu-bootstrap, diakses pada 2 juli 2021.

Nurrahmi, H., \& Susanto, A. (2018). Perancangan Sistem Informasi Dashboard Penjualan dan Sales Report. Sainstech: Jurnal Penelitian Dan Pengkajian Sains Dan Teknologi, 28(2). https://doi.org/10.37277/stch.v28i2.240

Palit, R. V., Rindengan, Y. D. Y., Lumenta, A. S. M., \& Palit, R. (2015). Rancangan Sistem Informasi Keuangan Gereja Berbasis Web Di Jemaat GMIM Bukit Moria Malalayang. 4(7), 7.

Putra, N. D. P. (n.d.). RANCANG BANGUN SISTEM INFORMASI MONITORING PERKEMBANGAN PROYEK BERBASIS WEB STUDI KASUS DI DINAS BINA MARGA DAN PEMANTUSAN. Jurnal Teknik Industri, 11(1), 9.

Rizky, Dimas. 2019. "Mengenal Prototyping", https://medium.com/dot-intern/sdlcmetode-prototype-8f50322b14bf.

\section{Copyrights}

Copyright for this article is retained by the author(s), with first publication rights granted to the journal.

This is an open-access article distributed under the terms and conditions of the Creative Commons Attribution license (http://creativecommons.org/licenses/by/4.0/) 